\title{
Quality of life and burden in carers for persons with Chronic Obstructive Pulmonary Disease receiving oxygen therapy ${ }^{1}$
}

\author{
Simone Cedano ${ }^{2}$ \\ Ana Rita de Cássia Bettencourt ${ }^{3}$ \\ Fabiana Traldi² \\ Maria Christina Lombardi Oliveira Machado ${ }^{4}$ \\ Angélica Gonçalves Silva Belasco ${ }^{3}$
}

Objective: to assess the quality of life and burden of caregivers to Chronic Obstructive Pulmonary Disease patients on Long-Term Oxygen Therapy and to investigate the factors influencing this burden. Method: this is an analytical, cross-sectional study of 80 persons with Chronic Obstructive Pulmonary Disease on Long-Term Oxygen Therapy who used the specialized outpatient center of the Federal University of São Paulo, and their carers. The following instruments were used: Medical Outcomes Studies 36 (SF-36), Caregiver Burden Scale (CBS) and the Katz Index, along with socio-demographic and clinical variables. Results: the most compromised scores on the carers' quality of life questionnaire were for Vitality and Mental Health. On the Caregiver Burden Scale, the domain which created the greatest burden for carers was the Environment. With the exception of Emotional Involvement, all the domains of quality of life were affected negatively by the domains of caregiver burden. Conclusion: it was shown that carers' quality of life was compromised and that they were overburdened with care tasks, confirming that assisting persons with Chronic Obstructive Pulmonary Disease is an important element in carers' quality of life.

Descriptors: Quality of Life; Pulmonary Disease, Chronic Obstructive; Caregivers; Oxygen Inhalation Therapy.

\footnotetext{
${ }_{1}^{1}$ Paper extracted from master's thesis "Qualidade de vida do paciente portador de DPOC em uso de oxigenoterapia domiciliar e seu cuidador", presented to Escola Paulista de Enfermagem, Universidade Federal de São Paulo, São Paulo, SP, Brazil. Supported by Coordenação de Aperfeiçoamento de Pessoal de Nível Superior (CAPES).

2 Master's students, Escola Paulista de Enfermagem, Universidade Federal de São Paulo, São Paulo, SP, Brazil.

${ }^{3}$ PhD, Adjunct Professor, Escola Paulista de Enfermagem, Universidade Federal de São Paulo, São Paulo, SP, Brazil.

${ }^{4}$ PhD, Physician, Hospital São Paulo, Universidade Federal de São Paulo, São Paulo, SP, Brazil.
}

Corresponding Author:

Simone Cedano

Rua Henrique de Sousa Queiros, 380, Apto. 81

Bairro: Penha de França

CEP: 03605-020, São Paulo, SP, Brasi

E-mail: simone.cedano@ig.com.br 


\section{Introduction}

Chronic Obstructive Pulmonary Disease (COPD) is preventable and treatable and has some extrapulmonary effects which can contribute to the severity of the individual's condition. The pulmonary component is characterized by the chronic limitation of the air flow, which is not totally reversible. The limitation of air flow is generally progressive and is associated with an exaggerated inflammatory response of the lungs to harmful particles or gases ${ }^{(1)}$.

COPD is a great challenge for public health, and is the fourth principal cause of death worldwide ${ }^{(1)}$. Oxygen therapy is one of the therapies currently available to reduce this mortality(2). Although it increases survival, the prolonged use of oxygen reduces the individual's independence due to the extensive reduction of the limitation of airflow and the restriction on movement imposed by the apparatus containing the oxygen. COPD's physical harm, associated with the use of the oxygen, frequently leads relatives to act as carers in helping with activities of daily living ( $A D L$ ), normally without the help of health professionals(2). It is known that the informal support system, also termed informal care, provided by relatives, neighbors, friends and community institutions, still constitutes the most important aspect of community social support( ${ }^{(3)}$.

The informal carer's tasks are uninterrupted and, unlike a transient event, demand responsibility and transform the individual's life. They constitute significant stressful events, creating a burden of care which requires the carer to redimension their life so as to try to adapt to the implications caused by the continuous provision of care, as their quality of life (QL) is compromised over time ${ }^{(4)}$.

The World Health Organization Quality of Life Group defined quality of life as "An individual's perception of their position in life in the context of the culture and value systems in which they live, and in relation to their goals, expectations, standards and concerns". This concept involves six domains: physical health, psychological, levels of independence, social relationships, environmental characteristics and spirituality ${ }^{(5)}$.

Considering the high prevalence of COPD in Brazil, the use of sources of oxygen for long periods of the day and the uninterrupted care dedicated to the patient, it was decided to undertake a study with the objectives of: assessing the carers' QL (SF-36) and burden of care (CBS); correlating the caregiver's QL (SF-36) and burden of care (CBS) and verifying the influence of the caregivers' socio-demographic and clinical characteristics on the burden of care (CBS).

\section{Method}

This study was approved by the Research Ethics Committee of the Federal University of São Paulo (UNIFESP), under number 0730/09, and all participants signed the Terms of Free and Informed Consent.

This was an analytical, cross-sectional study and took place between July 2009 and June 2011, with persons with COPD on Long-Term Oxygen Therapy (LTOT) and their respective carers. The patients making up the sample were attended at the Oxygen Therapy Outpatient Center of the São Paulo Hospital, coordinated by the Department of Pneumology of the Federal University of São Paulo (UNIFESP).

These patients were staged and classified, in accordance with the GOLD (Global Initiative for Chronic Obstructive Lung Disease) document. Brazilian, American and European COPD Societies adopt the criteria defined by this document ${ }^{(1)}$.

All the patients diagnosed with COPD according to the GOLD criteria, who had used LTOT for three months or more, who stated that they had a carer aged over 18 years old and who had received care from the same carer for at least three months were eligible to take part in the study.

All the patients or carers were interviewed separately by one of the two researchers, trained for this purpose, in a private environment prior to their medical consultations. For the patients, the sociodemographic data (sex, age, schooling, marital situation, professional situation, per capita income) and the clinical and laboratorial data (severity of the disease, partial pressure of oxygen in arterial blood, time (hours/ day) and months using oxygen) and Katz Index were collected. For the carers, socio-demographic data (sex, age, schooling, marital situation, professional situation, per capita income, type of relationship with the patient and whether the carer lived with the patient or not) was collected, as was clinical data (comorbidities, duration of comorbidities and use of medications) and characteristics of the role of the carer (how long the person had been the carer and hours per day spent carrying out care).

The generic questionnaire Medical Outcomes Study Questionaire 36-Item Short Form Health Survey (SF-36), translated and validated for Brazil(6), was chosen for assessing the carers' QL. This is composed of 36 items, divided in eight domains: Vitality (VT), physical 
functioning (PF), bodily pain (BP), general health $(\mathrm{GH})$, role physical (RP), role emotional (RE), social functioning (SF) and mental health (MH). The score varies from zero (the worst result) to 100 (the best result).

The Caregiver Burden Scale (CBS) is a scale used for measuring the subjective impact produced on caregivers' lives by the care given to patients with chronic illnesses. It was translated, culturally adapted and validated for Brazil(6). It contains 22 questions, divided into five domains: general strain, isolation, environment, emotional involvement and disappointment, and it is possible to calculate a final score. The responses' scores vary from one to four, corresponding to 'never', 'rarely', 'sometimes' and 'frequently'. The total score for each domain is expressed by a number varying between one (least burden) and four (most burden)(6).

The assessment of the patients' level of dependence was made using the Katz Index, an instrument developed to assess functionality in Activities of Daily Living (ADL). This instrument measures the individual's ability to perform specified activities and verifies the independence or degree of compromise shown in doing so(7).

The modified scale was used here. This evaluates six activities of daily living (washing oneself, getting dressed, feeding oneself, going to the toilet, transferring and continence), and its classification varies from zero (independence for $A D L$ ) to six (dependence for all the ADL)(7).

For the carer, the five domains of the CBS were considered to be dependent variables, and sex, age, comorbidities, use of medications and length of time spent as a carer were considered independent variables. For the patient, the variables classified as independent were: sex, oxygen flow, severity of the disease and the Katz Index.

The data was analyzed using the statistical software JMP/SAS version 8.0.2- 2009. The ShapiroWilk test was used to verify the shape of the distribution of the population and the quality of the adjustment of the samples. The Wilcoxon and Chi-Squared test were carried out to analyze the associations between the categorical variables and the domains of the Caregiver Burden Scale, and the Pearson's co-efficient correlation (r) and ANOVA were used to analyze the numerical variables. The Pearson coefficient correlation was used in the analysis of the quantitative variables. Regarding the classification used for interpreting the strengths of the correlations, this study used the classification which considers values up to 0.30 to indicate weak correlation; values from 0.30 to 0.50 to be of moderate magnitude and values over 0.50 , strong magnitude(8). Multiple linear regression models were constructed to verify the influence of the carers' socio-demographic and clinical characteristics in the total score of the CBS. The level of significance in all the analyses carried out was considered to be $5 \%$.

\section{Results}

The data from Table 1 (below) presents the sociodemographic and economic characteristics of the 80 patients and carers assessed in this study.

Table 1 - Socio-demographic and economic characteristics of patients and their carers. São Paulo, SP, Brazil, 2011

\begin{tabular}{|c|c|c|}
\hline Characteristics & $\begin{array}{c}\text { Carers } \\
\mathrm{N}=80\end{array}$ & $\begin{array}{c}\text { Patients } \\
\mathrm{N}=80\end{array}$ \\
\hline \multicolumn{3}{|l|}{ Sex } \\
\hline Female & $65(81.3)$ & $41(51.3)$ \\
\hline Male & $15(18.7)$ & $39(48.7)$ \\
\hline Age (years) & $48.7 \pm 15.6(18-84)$ & $69.6 \pm 9.1(48-89)$ \\
\hline \multicolumn{3}{|l|}{ Schooling } \\
\hline Illiterate & $2(2.5)$ & $14(17.5)$ \\
\hline Junior High & $35(43.7)$ & $51(63.7)$ \\
\hline Senior High & $34(42.5)$ & $12(15)$ \\
\hline University & $9(11.3)$ & $3(3.8)$ \\
\hline \multicolumn{3}{|l|}{ Marital situation } \\
\hline Single & $16(20)$ & $10(12.5)$ \\
\hline Married & $57(71.3)$ & $44(55)$ \\
\hline Widowed & $7(8.7)$ & $26(32.5)$ \\
\hline \multicolumn{3}{|l|}{ Professional situation } \\
\hline Active & $37(46.3)$ & 0 \\
\hline Retired & $19(23.7)$ & 74 (92.6) \\
\hline
\end{tabular}


Table 1 - (continuation)

\begin{tabular}{|c|c|c|}
\hline Characteristics & $\begin{array}{c}\text { Carers } \\
\mathbf{N}=80\end{array}$ & $\begin{array}{c}\text { Patients } \\
\mathrm{N}=80\end{array}$ \\
\hline Housewife/husband & $11(13.7)$ & $3(3.7)$ \\
\hline Unemployed & $13(16.3)$ & $3(3.7)$ \\
\hline Per capita income (minimum salaries) & & $1.57(0.20-11.11)$ \\
\hline \multicolumn{3}{|l|}{ Type of relationship } \\
\hline Daughter & $33(41.2)$ & \\
\hline Wife & $22(27.5)$ & \\
\hline Son & $6(7.5)$ & \\
\hline Husband & $6(7.5)$ & \\
\hline Others* & $13(16.3)$ & \\
\hline Lived with patient & $80(100)$ & \\
\hline
\end{tabular}

Values were expressed in percentages (\%) or mean \pm Standard Deviation (Minimum - Maximum Values); *(brother, brother-in-law, father-in-law, grandson/ daughter, nephew, son-in-law, daughter-in-law and friend)

Of the 80 persons with COPD using LTOT, 41 $(51.3 \%)$ were female, 44 (55\%) were married, and most had little schooling. The mean age was 69.6 years ( \pm 9.1 ), varying from 48 to 89 years.

The carers had a mean age of 48.7 years, and the majority were female, married, with little schooling and were members of the families - above all, daughters and wives.

Table 2 shows the patients' clinical characteristics and their levels of dependency and comorbidities, as well as the variables related to the care and morbidities presented by the carers.

Table 2 - Distribution of patients and carers, according to the clinical and care characteristics. São Paulo, SP, Brazil, 2011

\begin{tabular}{|c|c|}
\hline \multicolumn{2}{|c|}{ Patients $(n=80)$} \\
\hline Severity of illness & \\
\hline Mild COPD & $2(2.5)$ \\
\hline Moderate COPD & $3(3.7)$ \\
\hline Severe COPD & $39(48.7)$ \\
\hline Very severe COPD & $36(45 \%)$ \\
\hline Partial Pressure of Oxygen $(\mathrm{mmHg})$ & $54.8 \pm 7.9(36.0-72.4)$ \\
\hline Months using $\mathrm{O}_{2}$ & $45.3 \pm 34.6(3-132)$ \\
\hline Time $\mathrm{O}_{2}$ used (hours/day) & $20.1 \pm 5.1(6-24)$ \\
\hline Katz Index & $0.47 \pm 0.98(0-4)$ \\
\hline \multicolumn{2}{|c|}{ Carers $(n=80)$} \\
\hline \multicolumn{2}{|l|}{ Duration of care } \\
\hline Less than 1 year & $4(6.3)$ \\
\hline $1-3$ years & $7(8.7)$ \\
\hline $4-5$ years & $20(25.0)$ \\
\hline Over 5 years & $48(60.0)$ \\
\hline Mean hours per day caring & $13.1 \pm 9.1(2-24)$ \\
\hline Carers with morbidities & $52(65)$ \\
\hline Cardiovascular & $36(45.0)$ \\
\hline Musculo-skeletal & $20(25.0)$ \\
\hline Endocrine* & $13(16.2)$ \\
\hline Respiratory $^{\dagger}$ & $10(12.5)$ \\
\hline
\end{tabular}

(continue...)
Table 2 - (continuation)

\begin{tabular}{lc}
\hline \multicolumn{2}{c}{ Patients $(\mathbf{n = 8 0 )}$} \\
\hline Depression & $8(10)$ \\
Gastro-intestinal $^{\ddagger}$ & $2(2.5)$ \\
Genito-urinary $^{\S}$ & $2(2.5)$ \\
Duration of morbidities (years) & $6.9 \pm 9.3(0.25-40)$ \\
Routine use of medications & $42(52.5)$ \\
\hline
\end{tabular}

Values were expressed in percentages (\%) or mean \pm standard deviation (minimum - maximum); *Diabetes mellitus, thyroid illnesses; † COPD, asthma, sinusitis, rhinitis; $\neq$ gastritis; § urinary incontinence.

The patients were shown to be hypoxemic, with reduced lung capacity, mostly severe or very severe, needing to remain attached to the $\mathrm{O}_{2}$ for several hours daily, and to have a low level of dependency for the ADL.

On average the carers had been providing care for 5 years and did so for an average of 13.1 hours per day. The majority had a health problem, with cardiovascular disturbances (high blood pressure, acute myocardial infarction and thrombosis) and musculo-skeletal problems (arthritis, arthrosis, scoliosis, kyphosis, osteoporosis and herniated discs) predominating, and needed medications as a matter of routine.

The data in Table 3 shows the mean scores of the domains of the SF-36 and the mean scores of the Caregiver Burden Scale (CBS), for the present study and for another Brazilian study undertaken in Ceará with COPD patients using LTOT and with their carers.

Limitations were observed in the different dimensions of the SF-36 analyzed, with the lowest results being vitality and mental health. Regarding the CBS, the most affected domain was the Environment.

Table 4 shows the significant correlations between the domains of the SF-36 and the scores for the CBS. All the domains of the SF-36 were influenced negatively by the CBS, with correlations ranging from weak to moderate, but significant. 
Table 3 - Mean values of the scores of the domains of the SF-36, and the CBS for carers of persons with COPD in LTOT, in the present study and another Brazilian study carried out in Ceará. São Paulo, SP, Brazil, 2011

\begin{tabular}{|c|c|c|}
\hline Domains of the SF-36 & $\begin{array}{l}\text { Present study } \\
\text { Mean (SD) }\end{array}$ & $\begin{array}{l}\text { Study by Pinto et al. } \\
\text { Mean (SD) }\end{array}$ \\
\hline Physical functioning & $77.7(22.5)$ & $72(27.74)$ \\
\hline Bodily Pain & $75.4(22.8)$ & $64.4(29)$ \\
\hline Role Emotional & $74.1(41.4)$ & $67.4(41.3)$ \\
\hline Social Functioning & $73.6(31.8)$ & $79.4(26)$ \\
\hline General Health & $73.6(25.9)$ & $61.2(29.07)$ \\
\hline Role Physical & 71.5 (37.9) & $68.4(38.67)$ \\
\hline Mental Health & $68.1(22.8)$ & $62(27.08)$ \\
\hline Vitality & $64.0(25.0)$ & $61.4(28.4)$ \\
\hline Domains of CBS & $\begin{array}{l}\text { Present study } \\
\text { Mean (SD) }\end{array}$ & $\begin{array}{l}\text { Study by Pinto et al. }{ }^{(6)} \\
\text { Mean (SD) }\end{array}$ \\
\hline Environment & $1.96(0.79)$ & $2.18(0.72)$ \\
\hline General Strain & $1.89(0.74)$ & $1.75(0.72)$ \\
\hline Disappointment & $1.76(0.81)$ & $1.67(0.67)$ \\
\hline Isolation & $1.74(0.79)$ & $1.63(1.0)$ \\
\hline Emotional Involvement & $1.44(0.60)$ & $1.96(0.88)$ \\
\hline Total & $1.80(0.64)$ & $1.79(0.62)$ \\
\hline
\end{tabular}

The scores' values are presented as means ( \pm standard deviation)

Table 4 - Coefficient of correlation between dimensions of the SF-36 of the carers and burden experienced by the carers, according to the domains of the Caregiver Burden Scale. São Paulo, State of São Paulo, Brazil, 2011

\begin{tabular}{|c|c|c|c|c|c|c|}
\hline Domains of the SF-36 & General strain & Isolation & Disappointment & $\begin{array}{c}\text { Emotional } \\
\text { involvement }\end{array}$ & Environment & Total \\
\hline Physical functioning & $-0.42^{*}$ & $-0.41^{*}$ & $-0.41^{*}$ & $-0.05^{\ddagger}$ & $-0.37^{*}$ & $-0.45^{*}$ \\
\hline Role physical & $-0.37^{*}$ & $-0.34^{*}$ & $-0.37^{*}$ & $-0.17^{\ddagger}$ & $-0.46^{*}$ & $-0.4^{*}$ \\
\hline Bodily pain & $-0.47^{*}$ & $-0.38^{*}$ & $-0.34^{*}$ & $-0.06^{\ddagger}$ & $-0.45^{*}$ & $-0.46^{*}$ \\
\hline General health & $-0.42^{*}$ & $-0.33^{\dagger}$ & $-0.50^{*}$ & $-0.17^{\ddagger}$ & $-0.34^{\dagger}$ & $-0.48^{*}$ \\
\hline Vitality & $-0.52^{*}$ & $-0.46^{*}$ & $-0.55^{\star}$ & $-0.23^{\dagger}$ & $-0.46^{*}$ & $-0.60^{*}$ \\
\hline Social functioning & $-0.62^{*}$ & $-0.67^{*}$ & $-0.64^{*}$ & $-0.33^{\dagger}$ & $-0.44^{*}$ & $-0.70^{*}$ \\
\hline Role Emotional & $-0.45^{\star}$ & $-0.31^{\dagger}$ & $-0.45^{\star}$ & $-0.25^{\dagger}$ & $-0.23^{\dagger}$ & $-0.43^{*}$ \\
\hline Mental health & $-0.55^{\star}$ & $-0.51^{*}$ & $-0.58^{*}$ & $-0.24^{\dagger}$ & $-0.41^{*}$ & $-0.62^{*}$ \\
\hline
\end{tabular}

$* p<0.001 ;+p<0.05 ; \neq p>0.05$

The domains of the SF-36 had a significant correlation ranging from weak to strong magnitude with the domains of the CBS, with the exception of the physical functioning, role physical, bodily pain and general health in relation to the CBS domain of emotional involvement, which did not have a significant correlation ( $p>0.05$ ).

Multiple linear regression analysis was carried out between the total score of the CBS and the carers' sociodemographic and clinical variables. The model presented a total for ' $r$ ' of 0.61 and the aspects which influenced the burden of care were: the presence of musculoskeletal morbidity in the carer $(r=0.36 ; p<0.0001)$ and the number of hours per day that the carer dedicates to care for the patient with COPD in LTOT $(r=0.25$, $p<0.003)$.

\section{Discussion}

One may observe in the study's results that the mean age of the persons with COPD was 69.6 years; $51.3 \%$ were women and the schooling of $46.2 \%$ reached junior high level. The patients were hypoxemic, dependent on a source of oxygen for a long period of each day, and $90 \%$ had severe or very severe COPD and had low levels of dependence, according to the Katz Index.

Although some studies have shown a predominance of men among persons with COPD, the GOLD document reports that studies undertaken in developed countries have shown the prevalence of COPD to be similar between the sexes - possibly explained by the changes in patterns of smoking among women ${ }^{(9-11)}$. 
In the present study, $55 \%$ of the patients were married, 92.6\% were retired and the majority had a low per capita income. A study undertaken in Rio Grande de Sul with a similar sample found similar results, with $67.4 \%$ of the patients married and $73.9 \%$ retired(10). An Iranian study also identified greater predominance of married people (88\%) and low per capita income among persons with COPD ${ }^{(12)}$.

In the present study, the carers' age varied between 18 and 84 years, with a mean of 48.7 . Studies carried out in Greece and Spain, with patients being mechanically ventilated in their homes, showed the carers to have a mean age of 47.9 and 51 years, respectively, confirming that the carers' mean age is below the patients' mean age $^{(13-14)}$.

The majority of the carers in the present study undertook professional activities outside the home, in addition to providing care for the patient with COPD in LTOT. Other studies undertaken with patients' carers in the same clinical conditions have also made similar findings. As the majority of carers are informal, relatives, and are not paid for the care tasks they perform, they have no way of meeting their needs without regular paid employment ${ }^{(13-14)}$.

In the present study the authors identified that the carers live with the patients and are mainly related to them, principally as daughters and spouses. This data is similar to that from other studies undertaken with carers $^{(6,13,15)}$. Socially, it is predominantly the women who perform the role of carer in differing cultures, in spite of the majority also having little schooling and low monthly income ${ }^{(6,13,15)}$.

In relation to how long the carer has been caring and the hours per week dedicated to the care, the study's findings ascertained that $85 \%$ of the carers had been providing care for over three years, and that they provided care for an average of 13.1 hours per day. This heavy demand for care can be explained by the fact that these patients have a chronic illness, $93.7 \%$ of the patients being severe or very severe, hypoxemic, and dependent on oxygen therapy for 20.1 hours per day. In the same way, a Chinese study with a similar sample identified a mean duration of care of eight years and for 11 hours per day ${ }^{(15)}$. In a study carried out in the United States of America, on the other hand, patients with chronic pulmonary disease received 11.9 hours/ week of informal care ${ }^{(16)}$.

The majority of the carers (65\%) had some type of illness, with cardiovascular and musculo-skeletal conditions being most prevalent. Another study, with a similar sample, reported $52.4 \%$ of the carers with some type of health problem ${ }^{(6)}$. A North American study undertaken with the carers of patients with a variety of pathologies showed that $27.1 \%$ of the carers had some type of illness and that the most prevalent were also those of the cardio-vascular system ${ }^{(17)}$.

In the present study, the most-compromised domains in the carers' QL, according to the SF-36, were vitality (64.06) and mental health (68.15), indicating that the carers were more prone to episodes such as fatigue, anxiety and signs and symptoms of depression. Similar data was ascertained in a Brazilian study carried out in Ceará, with carers of COPD patients, who showed reduced QL scores in the domains of vitality (61.4), general health perceptions (61.2) and mental health $(62)^{(6)}$. A Chinese study with a similar sample evidenced lower scores in the domains of vitality (58) and general state of health $(56)^{(15)}$. In Chicago, a study with persons with terminal illness, including COPD, showed worse QL scores in the domains of vitality (53.4) and general health perceptions $(64.8)^{(18)}$.

Similarly to this study, the other research projects cited above found better scores in the domain of physical functioning, with scores of 82 in Ceará, 72 in China and 74.3 in Chicago $(6,15,18)$.

In the present study, the total score for care burden experienced by the carers (1.8) was similar to the other Brazilian study which assessed carers of patients with COPD $(1.79)^{(6)}$; higher than that of carers for COPD patients in Australia (1.59) and lower than the total burden of carers for people with chronic renal failure receiving hemodialysis (2.07), and the burden of carers for people with Alzheimer's (2.18)(19-21). The CBS domain which showed the greatest burden on the carers, in the present study, was the environment, while Australian carers had their best score in this domain. The carers in the present research experienced more problems related to access to medical services, transport, medications and the unsuitability of the domestic environment for care, in relation to the Australian carers $^{(22)}$.

The CBS domains had an inverse correlation with all the domains of the SF-36, with the exception of emotional involvement (CBS), which had no correlation with physical functioning, role physical, bodily pain and general health (SF-36). In contrast with the other domains of the CBS, Emotional Involvement was the domain which least affected the carer's quality of life. The carer's quality of life, therefore, is not much harmed by feelings of hate, offense, shame or embarrassment 
at the patient's behavior. A study with a similar sample found a negative correlation between the total CBS score and the summarized physical $(r=-0.42)$ and mental $(r=-0.49)$ components of the SF-36(6). Another research project undertaken with carers for persons with chronic illnesses, including COPD, showed that the total score of the CBS had a negative correlation with all the domains of the SF-36(18). The greater the burden of care experienced by the carers, the worse their quality of life in the various domains.

In the present study, the QL domains of carers of persons with COPD in LTOT who suffered the worst influence of the total burden were, according to the SF36 , social role functioning, mental health and vitality, which indicates that the carers with the greatest burden of care had worse social integration, greater lack of emotional control, fatigue and worse levels of energy.

All the carers in this study lived with the patient and undertook the care activity for an average of 13.1 hours per day. The more hours spent caring for the patient, the greater the carer's burden was. Studies carried out with people caring for older adults show that living with the patient and dedicating many hours to care create greater burden on the carer, according to the Zarit Burden Interview scale(22-23).

In the present study, as well as in studies undertaken with carers for older adults, cardiovascular and musculo-skeletal pathologies represent the principal illnesses manifested by the carers $^{(24)}$.

In this study nearly all the carers with musculoskeletal problems were women and having this sort of illness, according to the multiple linear regression analysis, was responsible for $36 \%$ of the burden experienced by the carer.

The carers' musculo-skeletal problems may be attributed to ergonomic factors and poor posture, which are present, above all in the physical aspect of the work with the patient, added to women's inherent weakness.

A study undertaken with women who provide care - health professionals - showed that the greatest causes of suffering among the female workers were musculoskeletal problems ${ }^{(25)}$. Despite the high prevalence of musculo-skeletal problems in informal carers in this study, the authors did not find works correlating burden of care with the pathologies of this system in the literature. Further research in this area should be carried out to clarify the possible association between the manifestation of musculo-skeletal problems, the number of hours of care provided, and the caregiver's burden.

\section{Final considerations}

Measures for preventing harm to carers' health and promoting their health need to be developed and implemented, as the compromising of the carers' health, the reduction in their quality of life and the burden of care they experience can compromise the care given to the person with COPD in LTOT, as well as leading to the illness of the carer.

Assessing the carers' quality of life and the factors which influence this is essential for planning integral actions in health which involve solutions for minimizing the detrimental effects resulting from the burden of care which they experience.

\section{References}

1. Global Initiative for Chronic Obstructive Lung Disease - GOLD. Bethesda: Global Initiative for Chronic Obstructive Lung Disease. Global strategy for the diagnosis, management, and prevention of chronic obstructive pulmonary disease updated 2010; [Acesso 1 Nov 2011]. Disponível em: http://www.goldcopd.org/ uploads/users/files/GOLDReport_April112011.pdf

2. Bártholo TP, Gomes MM, Noronha Filho AJ. DPOC o impacto da oxigenoterapia domiciliar no tratamento. Pulmão. 2009;1(1):79-84.

3. Duca GF, Thumé E, Hallal PC. Prevalência e fatores associados ao cuidado domiciliar a idosos. Rev Saude Publica. 2011;45(1):113-20.

4. Inouye K, Pedrazzani ES, Pavarini SCI, Toyoda CY. Perceived quality of life of elderly patients with dementia and family caregivers: evaluation and correlation. Rev. Latino-Am. Enfermagem. 2009;17(2):187-93.

5. Fleck MPA. O instrumento de avaliação de qualidade de vida da Organização Mundial da Saúde (WHOQOL-100): características e perspectivas. Ciênc Saúde Coletiva. 2000;5(1):33-8.

6. Pinto RA, Holanda MA, Medeiros MMC, Mota RMS, Pereira EDB. Assessment of the burden of caregiving for patients with chronic obstructive pulmonary disease. Respir Med. 2007;101:2402-8.

7. Duarte YAO, Andrade CL, Lebrão ML. O Índex de Katz na avaliação da funcionalidade dos idosos. Rev Esc Enferm USP. 2007;41(2):317-25.

8. Ajzen J. Fishbein M. Overview. In: Ajzen J. ; Fishbein M. Understanding attitudes and predicting social behavior. New Jersey: Prentice-Hall; 1998.

9. Dransfield MT, Washko GR, Foreman MG. Gender Differences in the Severity of CT Emphysema in COPD. Chest. 2007;132(2):464-70. 
10. Godoy DV, Godoy RF. Redução nos níveis de ansiedade e depressão de pacientes com doença pulmonar obstrutiva crônica (DPOC) participantes de um programa de reabilitação pulmonar. J. Pneumologia. $2002 ; 28(3): 120-4$

11. Global Initiative for Chronic Obstructive Lung Disease - GOLD [homepage on the Internet]. Bethesda: Global Initiative for Chronic Obstructive Lung Disease. [cited 2012 Feb 2]. Global strategy for the diagnosis, management, and prevention of chronic obstructive pulmonary disease 2006. [Adobe Acrobat document, 100p.] Available from: http://www.goldcopd.org/ uploads/users/files/ GOLDReport2006_0122.pdf

12. Aslani J, Nouhi S, Farahani MAA, Lankarani MM, Saadat SH, Ghanei M. The Socioeconomic Status and Quality of Life in Patients with Chronic Obstructive Pulmonary Disease. Tanaffos. 2007;6(2):38-45.

13. Tsara V, Serasli E, Voutsas V, Lazarides V, Christaki P. Burden and Coping Strategies in Families of Patients under Noninvasive Home Mechanical Ventilation. Respiration. 2006;73:61-7.

14. Alvarez RF, Cuadrado GR, Lacalzada CC, Morales RG, Blanco JAG, Martín IG. Home Mechanical Ventilation: Dependency and Burden of Care in the Home. Arch Bronconeumol. 2009;45(8):383-6.

15. Lee E, Lum CM, Xiang YT, Ungvari GS, Tang WK. Psychosocial Condition of Family Caregivers of Patients with Chronic Obstructive Pulmonary Disease in Hong Kong. Hong Kong J Psychiatry. 2010;20(4):180-5.

16. Langa KM, Fendrick AM, Flaherty $K R$, Martinez FJ, Kabeto MU, Saint S. Informal Caregiving for Chronic Lung Disease Among Older Americans. Chest. 2002;122(6):2197-203.

17. Schulz R, Beach SR. Caregiving as a Risk Factor for Mortality. The Caregiver Health Effects Study. JAMA. 1999;282(23):2215-19.

18. Hughes SL, Giobbie-Hurder A, Weaver FM, Kubal JD, Henderson W. Relationship Between Caregiver Burden and Health-Related Quality of Life. The Gerontologist. 1999;39(5):534-45.

19. Appleton S, Adams R, Porter S, Peacock M, Ruffin R. Sustained Improvements in Dyspnea and Pulmonary Function 3 to 5 Years After Lung Volume Reduction Surgery. Chest. 2003;123(6):1838-46.

20. Belasco AG, Sesso R. Burden and quality of life of caregivers for hemodialysis patients. Am J Kidney Dis. 2002;39(4):805-12.

21. Lemos ND, Gazzola JM, Ramos LR. Cuidando do paciente com Alzheimer: o impacto da doença no cuidador. Saúde Soc. 2006;15(3):170-9.
22. Gratão ACM. Sobrecarga vivenciada por cuidadores de idosos na comunidade. [tese doutorado]. Ribeirão Preto (SP): Escola de Enfermagem de Ribeirão Preto da Universidade de São Paulo; 2010.

23. Borges LL, Albuquerque CR, Garcia PA. O impacto do declínio cognitivo, da capacidade funcional e da mobilidade de idosos com doença de Alzheimer na sobrecarga dos cuidadores. Fisioter Pesq. 2009;16(3):246-51.

24. Gonçalves LHT, Alvarez AM, Sena ELS, Santana LWS, Vicente FR. Perfil da família cuidadora de idoso doente/ fragilizado do contexto sociocultural de Florianópolis, SC.Texto Contexto Enferm. 2006;15(4):570-7.

25. Raffone AM, Hennington EA. Avaliação da capacidade funcional dos trabalhadores de enfermagem. Rev. Saúde Pública 2005;39(4):669-76.
Received: Aug. 27th 2012 Accepted: Mar. $25^{\text {th }} 2013$ 